\title{
Safety and Efficacy of a New Posterior Chamber Phakic Intraocular Lens in Cases of High Myopia: Early Results
}

This article was published in the following Dove Press journal: Clinical Ophthalmology

\author{
Praveen Subudhi ${ }^{1,2}$ \\ Sweta Patro' \\ Prateek Agarwal ${ }^{3}$ \\ Zahiruddin Khan ${ }^{2}$ \\ B Nageswar Rao Subudhi' \\ Chandan Mekap' \\ Asutosh Padhi ${ }^{4}$ \\ 'Cornea and Refractive surgery services, \\ Ruby Eye Hospital, Berhampur, Odisha, \\ India; ${ }^{2}$ Ophthalmology Department, \\ Hitech Medical College, Bhubaneswar, \\ Odisha, India; ${ }^{3}$ Cleveland Clinic, Abu \\ Dhabi, United Arab Emirates; ${ }^{4}$ George \\ Clinicals, Hyderabad, India
}

Correspondence: Praveen Subudhi Ruby Eye Hospital, Govinda Vihar, Sushruta Nagar, Ganjam, Berhampur, Odisha, India

Email subudhipraveen@gmail.com
Purpose: To demonstrate the visual outcomes of a foldable, hydroxy ethyl-methacrylate, single-piece, posterior chamber phakic intraocular lens (pIOL).

Study Type: Retrospective study.

Materials and Methods: Patients presenting with moderate to high myopia who underwent surgical correction with a posterior chamber phakic IOL (refractive intraocular lens, phakic intraocular lens, Appasamy Associates, Chennai, India) were retrospectively reviewed. Only patients with at least one-year follow-up were included. Manifest refraction, uncorrected distance visual acuity (UDVA), corrected distance visual acuity (CDVA), endothelial cell density (ECD), and pIOL vault were analyzed 1, 3, 6, and 12 months after surgery. Intraoperative and postoperative events were recorded in all cases.

Results: The study included 30 eyes from 15 patients. The mean patient age was $25.8 \pm 3$ years. The spherical equivalent of manifest refraction was $-11.47 \pm 4.38 \mathrm{D}$ preoperatively and $-0.44 \pm$ $0.55 \mathrm{D}$ postoperatively. The preoperative CDVA was $0.17 \pm 0.12 \log \mathrm{MAR}$. The postoperative UDVA was $0.053 \pm 0.11 \log$ MAR (min: -0.17 and max: 0.2 ) and $0.019 \pm 0.091 \operatorname{logMAR}$ (min: -0.17 and max: 0.2 ) at the end of 1 month and 6 months, respectively. At the end of the 12-month visit, the postoperative UDVA was $0.032 \pm 0.094$, and the safety index was 2.42 . The mean ECD was 2639 cells $/ \mathrm{mm}^{2}$ (min: 2389 and max: 2993 with SD: 139.53) at the preoperative visit and 2445 cells $/ \mathrm{mm}^{2}$ (min: 2050 and max: 2701) at the 12 -month visit (5.8\% loss, p less than 0.001 ). ECD loss from 6 months to 12 months was not statistically significant. No significant cataract formation, significant endothelial cell loss, glaucoma, uveitis, or any other vision-threatening complication were observed.

Conclusion: Based on postoperative experience, we found that RIL phakic IOLs are safe and effective for treating high myopia at short-term follow-up.

Keywords: refractive intraocular lens, RIL, myopia, phakic lens

Phakic Intraocular lens (IOL) have become the basic procedure for high degrees of refractive errors. ${ }^{1-3}$ Patients with myopia beyond $-10 \mathrm{D}$ prefer to undergo phakic IOLs instead of keratorefractive procedures globally. ${ }^{4}$ Refractive surgeons have determined that keratorefractive procedures for high myopes $(>-8.0 \mathrm{D})$ and corneas with $>40 \%$ tissue alteration weaken the cornea, significantly increasing the risk of regression and ectasia. ${ }^{5}$ In contrast, phakic IOLs that bypass the cornea provide excellent postoperative vision, maintain accommodation, and avoid the anterior pull of the peripheral vitreous, thus obviating the risk of peripheral retinal tears, and they are reversible. ${ }^{6}$ The most common types of lenses implanted during the last two decades, and considered safe and effective are the iris-claw and collamer posterior chamber 
phakic IOLs. The cardinal risks associated with implantation of them are long-term endothelial cell loss (particularly in iris-claw pIOLs), cataract formation, pigment dispersion and raised intraocular pressure. ${ }^{7-12}$ Some newer pIOLs models have emerged during the last few years, but there is no evidence regarding their long-term safety and efficacy with a follow-up time of 5 years or longer. ${ }^{13-17}$ The current paper demonstrates 1-year visual outcomes of a newer type of phakic IOL (Refractive Intraocular Lens (RIL), Appasamy Associates Inc.) in eyes with moderate to high myopia. To the best of our knowledge, this is the first report of this model.

\section{Materials and Methods}

This retrospective clinical study included the medical records of 30 eyes in 15 patients who underwent RIL at Ruby Eye Hospital, Berhampur, Odisha, India. All patients provided informed written consent in congruence with the tenets of the Declaration of Helsinki. The study was taken approval from the Ruby Eye Hospital ethics board, reference number REH-2017-3.

The exclusion criteria were age less than 18 years, endothelial density of less than 2300 cells $/ \mathrm{mm}^{2}$, endothelial guttae, macular scars, previous corneal surgery, an anterior chamber depth calculated from the endothelium of less than $2.8 \mathrm{~mm}$, corneal astigmatism greater than 3

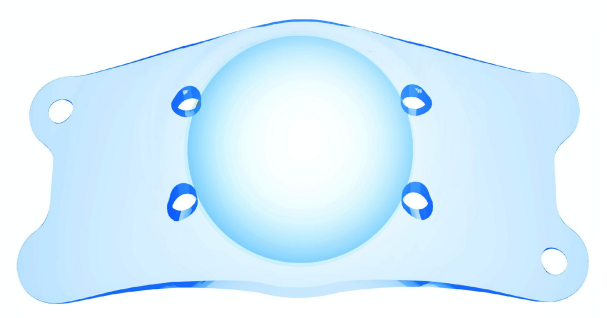

A

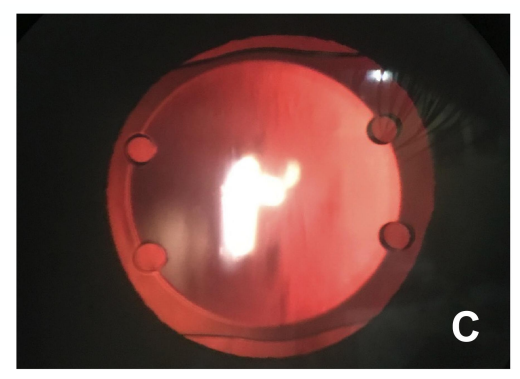

diopter (D), keratoconus and systemic endocrinal diseases (diabetes mellitus and thyroid disorders).

\section{Description of the Refractive Intraocular Lens Phakic IOL (RIL) (Figure IA)}

The RIL Phakic Intraocular Lens used in this study had a biconcave monofocal design. It was made of 2-hydroxyethyl methacrylate, which is a monomer based on methacrylic acid. It was a single-piece hydrophilic pIOL with an optic diameter of $5.75 \mathrm{~mm}$. It had a central vault of 1000 to 1600 microns, and the overall length ranged from $11.50 \mathrm{~mm}$ to $14.00 \mathrm{~mm}$, with increments of $0.25 \mathrm{~mm}$. The lens's thickness at the center varied from 150 to 450 microns, and the peripheral haptic thickness ranged from 100 to 140 microns. It had four holes in the optic region with a diameter of $0.55 \mathrm{~mm}$ for the smooth flow of aqueous fluid from posterior chamber to anterior chamber. It had two holes along the haptic plates for the determination of the vault, loading of the lens in the cartridge and implantation of the IOL in the posterior chamber. It had two curves in the haptic plates that had blended and polished edges.

\section{Preoperative Examination}

Before RIL implantation, patients underwent comprehensive ophthalmologic examinations including
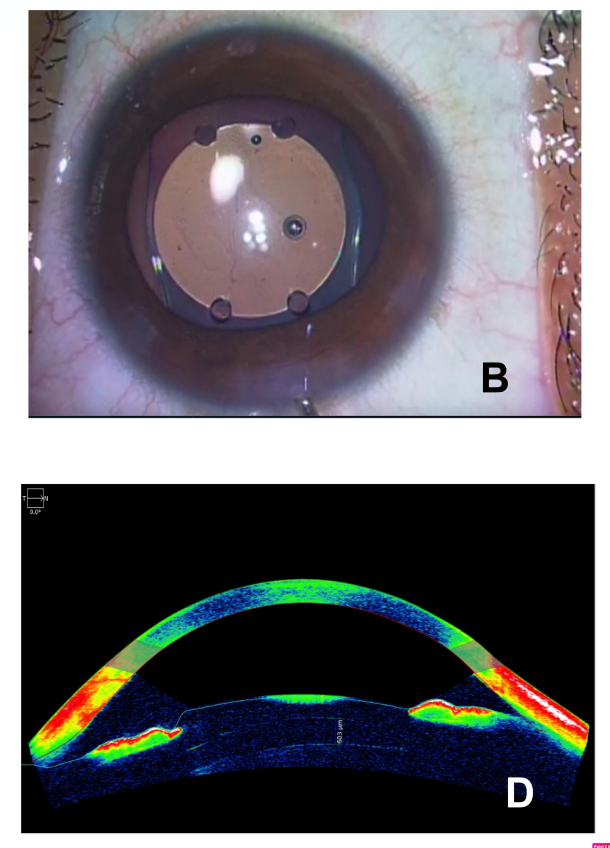

Figure I (A) Computer graphic of Refractive intraocular lens. (B) Intra-operative View of RIL under surgical microscope. (C) Retro-illumination view with slit lamp Biomicroscope. (D) Vault Height assessment with anterior segment OCT (Zeiss Inc., Jena, Germany). 
refraction (objective, manifest, cycloplegic); uncorrected (UDVA) and corrected (CDVA) distance logMAR visual acuities; slit-lamp evaluation; Goldmann applanation tonometry; pupil size, anterior chamber depth and corneal topography (pentacam, Oculus); corneal endothelial cell count (Noncon Robo, Konan Medical), optical biometry (IOLMaster, Carl Zeiss Meditec AG), and measurements of the white-to-white (WTW) distance by digital calipers (Figure 2); binocularity evaluation by performing TNO stereopsis test; and fundoscopy (by indirect ophthalmoscopy).

\section{RIL Power Calculation}

The RIL with appropriate power and diameter was calculated by furnishing three parameters to the company. The white-to-white distance was measured with digital calipers and the anterior chamber depth recorded from corneal endothelium with Pentacam (OCULUS Optikgeräte $\mathrm{GmbH}$, Wetzlar, Germany) and subjective refractive error.

\section{YAG Peripheral Iridotomy}

All patients underwent Nd.YAG peripheral iridotomy with Visulas YAG III lasers (Zeiss inc., Jena, Germany) to prevent postoperative pupillary block glaucoma.

\section{Surgical Technique. (Video I)}

Pupillary dilatation was performed by instilling 10\% topical tropicamide-phenylephrine every 10 minutes for 1 hour prior to the procedure. One drop of ketorolac eye drops was administered 1 hour prior to implantation. Surgery was performed under topical anesthesia by administering proparacaine eye drops every 5 minutes half an hour before the procedure. Loading of the RIL into the butterfly cartridge was performed initially. Hydroxy-propyl methylcellulose viscoelastics were injected into the cannula and base of the butterfly cartridge. The RIL with the vault facing up and the hole of the leading haptic plate located on the top right side was placed over the base of the butterfly cartridge. With the help of plain-angled forceps, the haptic and optic plates were tapped for accommodation

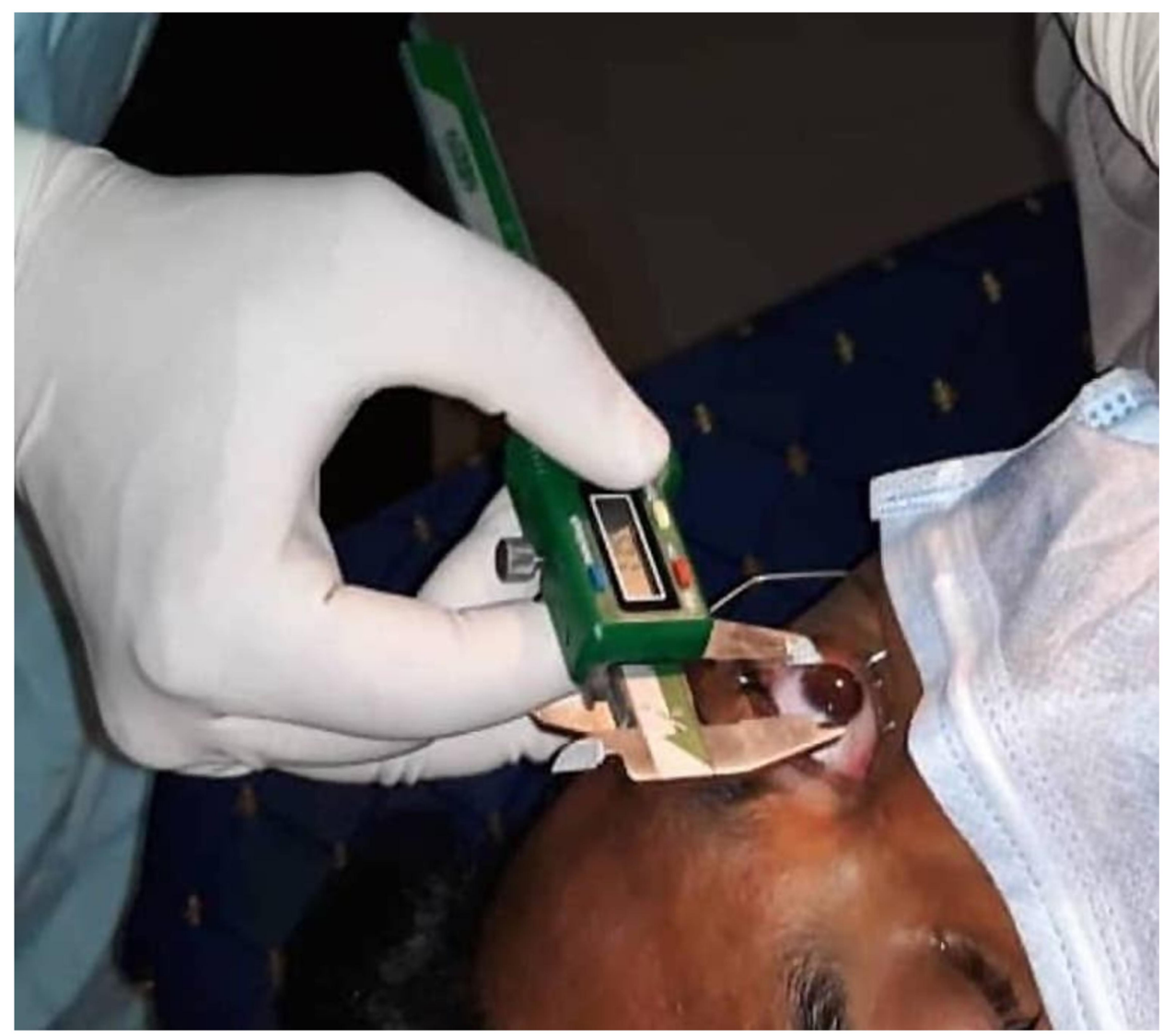

Figure 2 Demonstrating Digital callipers to measure white to white diameter of cornea. 
along the base, followed by the closure of the wings, ensuring that the lens was not engaged in the wings. Next, it was inserted into the plunger and was pushed forward to observe the smooth forward movement of the RIL. Eventually, a self-sealing $2.8 \mathrm{~mm}$ self-sealing clear corneal incision was made in the temporal quadrant of the eye. Two side ports were made at diagonally opposite quadrants to guide the haptic plate into the sulcus. Hydroxy-propyl methyl cellulose was injected into the anterior chamber to create a space between the cornea and capsule of the anterior lens. The bore of the butterfly cartridge was introduced into the $2.8 \mathrm{~mm}$ incision, and the plunger was pushed forward to observe the smooth unfolding of the RIL in the anterior chamber, ensuring that the vault was facing up by observing the leading haptic hole, which always remained on the top right-hand side. Once $50 \%$ of the RIL underwent the desired unfolding, the rest of the lens was pushed forward into the anterior chamber. With the help of smooth guidance, the haptic plates were initially pushed behind the iris, with the leading haptic plate followed by the trailing haptic plate. Finally, the complete removal of viscoelastics was performed using a Simcoe cannula/irrigation and aspiration cannula (Figure 1B). The viscoelastic behind the RIL was removed by gentle tapping of the centre of the optic. At the end, intracameral preservative-free moxifloxacin was introduced.

\section{Postoperative Follow-Up}

Follow-up visits were scheduled on the days 1, 7 and 30 after surgery, at 6 months and yearly thereafter. Evaluations included uncorrected distance visual acuity (UCVA) and corrected distance visual acuity (CDVA) in $\log$ MAR units, slit-lamp examinations of the position of RIL (Figure 1C), intraocular pressure and fundus examinations. Vault assessment was performed at each visit with the help of anterior segment OCT (Figure 1D).

\section{Outcome Parameters}

The primary outcome measure was uncorrected distance visual acuity, and the secondary outcome measures were vault height and endothelial cell count.

\section{Statistical Analysis}

Statistical analysis was performed using SPSS software. The normality of the data was checked by the Kolmogorov-Smirnov test and analyzed using paired $\mathrm{t}$ tests, Wilcoxon rank-sum tests, or analysis of variance
Table I Demographics of the Study

\begin{tabular}{|l|l|l|l|}
\hline & Demographics & $\begin{array}{l}\text { Mean } \pm \\
\text { SD }\end{array}$ & $\begin{array}{l}\text { Min/ } \\
\text { Max }\end{array}$ \\
\hline I & Age (Yrs) & $25.8 \pm 2.6$ & $19 / 30$ \\
2 & Spherical equivalent (D) & $-11.4 \pm 4.3$ & $-25 /-6$ \\
3 & White to white diameter (mm) & $11.8 \pm 0.4$ & $1 \mathrm{II/2.5}$ \\
4 & Axial length (mm) & $26.4 \pm I .5$ & $24.4 / 31.3$ \\
5 & Anterior chamber depth from corneal & $3.2 \pm 0.2$ & $2.8 / 3.5$ \\
& endothelium (mm) & $44.5 \pm 1.4$ & $42 / 48.3$ \\
6 & Flat Keratometry (D) & $45.7 \pm 1.9$ & $43 / 50.3$ \\
7 & Steep keratometry (D) &
\end{tabular}

with multiple comparisons, where appropriate, to determine significant differences in refractive, visual, and adverse outcomes. The results are presented as the mean and standard deviation. Differences were considered statistically significant when the $\mathrm{p}$ value was less than 0.05 .

\section{Results}

A total of 30 eyes from 15 patients were included in the study. Ten patients were male, and 15 patients were female. All patients underwent bilateral RIL implantation. The patient demographics are described in Table 1.

\section{Preoperative and Postoperative Visual Acuity (Figures 3D and 4B)}

The preoperative mean uncorrected visual acuity (UCVA) recorded was $1.266 \operatorname{logMAR}$ (max: 1 and min: 1.6, std dev: 0.17 and variance: 0.029 ), and the corrected distance visual acuity (CDVA) recorded was $0.173 \operatorname{logMAR}$ (max: 0, min: 0.4 , std dev: 0.128 and variance: 0.016 ). The postoperative mean UCVA at 1 month was $0.053 \log$ MAR (SD: 0.11, max: -0.17 and min: 0.2 , $p$ value $<0.0001$ ), at 6 months was 0.019 $\operatorname{logMAR}$ (SD: 0.09 , max: -0.17 and min: 0.2 , p value $<0.0001$ ) and at 12 months was $0.032 \operatorname{logMAR}$ (SD 0.09, max: -0.17 and min: 0.3, p-value: $<0.0001$ ) (Figure 3). Considerable improvement in post-operative uncorrected visual acuity (UCVA) was observed compared to preoperative corrected distance visual acuity (CDVA) and it was highly significant $(p<0.05)$. (Figure $4 \mathrm{~A})$ Cohen's $d=$ [mean postoperative UCVA $(0.0320)$ - mean preoperative CDVA (0.17)] $/ 0.106066=1.301076$, Glass's delta $=(0$. $032-0.17) / 0.12=1.15$, and Hedges' $g=(0.032-0.17) /$ $0.106066=1.301076$ were calculated at the end of 12 months of the study to determine the success of procedure, which was found to be successful. 


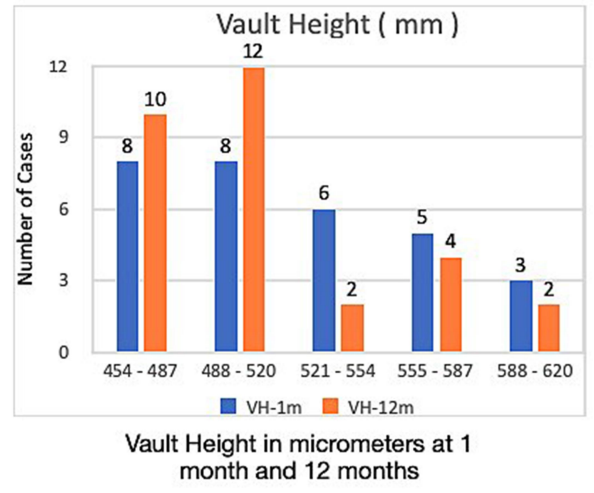

A
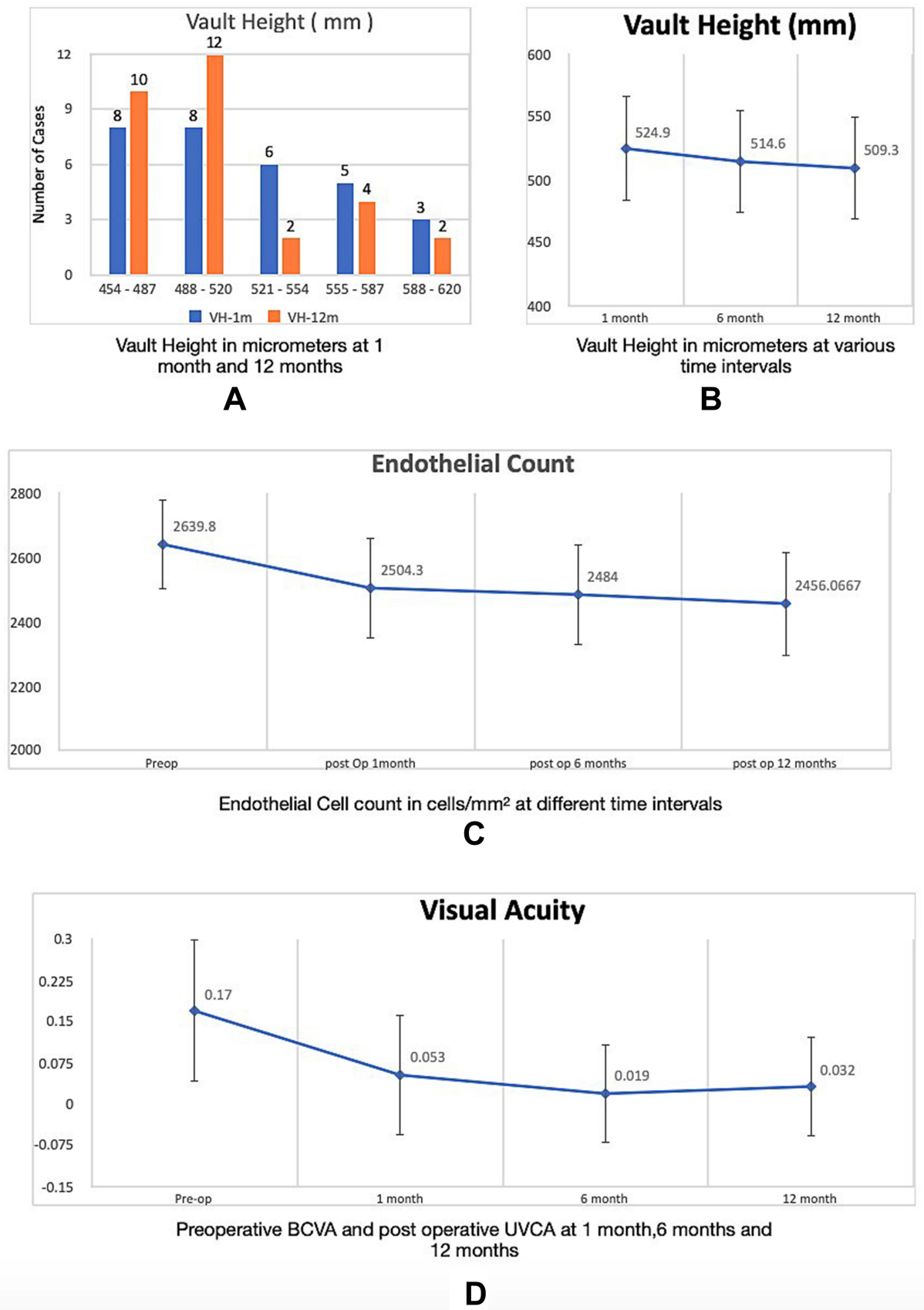

Figure 3 (A) Vault height (microns) at various time points. (B) Vault Height in micro-metres Comparison at I month and 12 months. (C) Endothelial Cell Count in cells/ $\mathrm{mm}^{2}$ at different time zones. (D) Preoperative CDVA and Post-Operative UCVA at Imonth, 6 months and 12 months.

\section{Vault Height (Figure 3A and B)}

Vault height was measured by anterior segment OCT (Zeiss Inc., Jena, Germany). The mean vault height at 1 month postoperatively was 524.9 microns (min: 470 and max: 611, SD: 41.5). It was 514.6 microns (min: 454 and max: 602, SD: 41) and 509.36 microns (min: 455 and max: 598, SD: 40.68), with p values of 0.1623 and 0.074 at the end of 6 months and 12 months, respectively.

\section{Specular Microscopy (Figure 3C)}

The mean preoperative endothelial cell count (ECC) was 2639 cells $/ \mathrm{mm}^{2}$ (min: 2389 and max: 2993 with SD: 139.53), which decreased by $5.15 \%$ to 2504 cells $/ \mathrm{mm}^{2}$ 


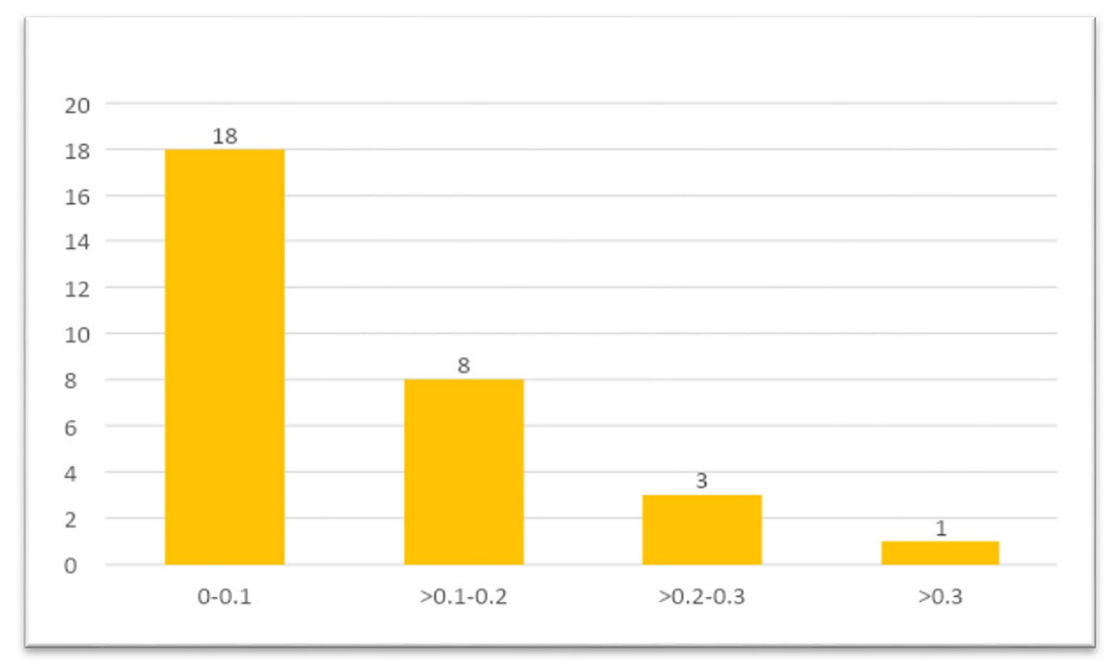

A

Number of eyes showing difference between post-operative UCVA and preoperative BCVA in Logmar Units

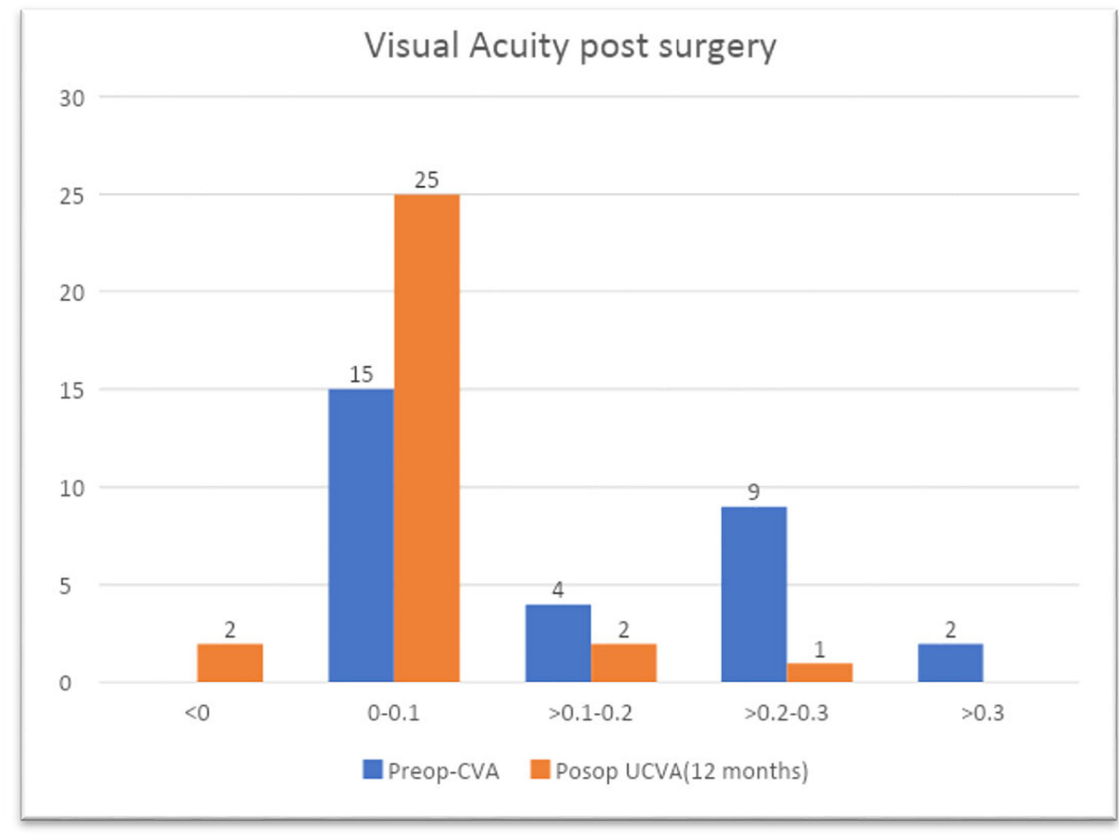

B

Preoperative BCVA vs Post-operative UCVA in Logmar Units

Figure 4 (A) Difference between post-operative UCVA and preoperative BCVA in Logmar units showing significant improvement with p value <0.05. (B) Preoperative CDVA vs Post-Operative UCVA at 12 months in Logmar units.

(min: 2185 cells $/ \mathrm{mm}^{2}$ and $\max : 2786$ cells $/ \mathrm{mm}^{2} \mathrm{p}=0.00038$ ) at 1 month POD. The mean endothelial cell count at 12 months showed a further reduction of $2.3 \%$ to 2445 cells/ $\mathrm{mm}^{2}$ (min: 2050 cells $/ \mathrm{mm}^{2}$ and max: 2701 cells $/ \mathrm{mm}^{2} \mathrm{p}$ value
$0.1215)$. There was a significant reduction in the endothelial cell count in comparison to the preoperative endothelial cell count at the end of 1 month; however, it remained stable with no significant reduction at the end of 12 months. 


\section{Safety Index}

The safety index was calculated by dividing the mean postoperative best-corrected visual acuity by the mean preoperative best-corrected visual acuity. The safety index at the end of the final visit was 2.42 .

\section{Complications}

None of the eyes developed cataracts, pupillary block glaucoma, iris pigment dispersion, retinal detachment or any other vision-threatening complication.

\section{Discussion}

In cases of myopia $>8 \mathrm{D}$ and those with insufficient corneal thickness, posterior chamber phakic intraocular lens implantation is capable of working successfully, providing accurate spectacle-free vision. ${ }^{18}$ This study focuses on the safety of a new intraocular phakic IOL. This is a retrospective observational case series of refractive intraocular lenses showing good results. Recent studies of a novel phakic IOL (IPCL with peripheral holes) by Care Group Inc. achieved a visual acuity of 20/40 or better in $90 \%$ of eyes. ${ }^{17}$ In our study, $100 \%$ of eyes achieved an unaided visual acuity of $20 / 40$ or better, and $73 \%$ of eyes could achieve $20 / 20$ or better. In addition, $10 \%$ of eyes had a vision of $20 / 16$ or better.

Similar to previous studies, our study demonstrated improvement in the mean uncorrected visual acuity from 1.266 logmar units to 0.053 units and showed no significant change for 12 months.

Furthermore, the postoperative residual refraction recorded value was similar to that of previously published studies. Alfonso et al, in a study of 182 eyes, demonstrated that $96.8 \%$ of eyes were within $\pm 1.0 \mathrm{D}$ of attempted correction at the 1-month follow-up. ${ }^{11}$ Sachdev et al, in a study of 134 eyes, demonstrated that $96.06 \%$ of eyes achieved a manifest refractive error within $\pm 1.0 \mathrm{D}$ of intended correction. ${ }^{16}$ Vasavada et al demonstrated residual refraction within $\pm 1 \mathrm{D}$ in $92 \%$ and $100 \%$ of eyes after 1 month and 6 months, respectively. ${ }^{19}$ Along similar lines, our study demonstrated that $96.6 \%$ of eyes had residual refraction within $\pm 1 \mathrm{D}$.

Postoperative vault height, rotational stability and preservation of the endothelium determine the success of phakic IOLs. Vault heights within the range of 250 to 750 microns are considered ideal to prevent cataract formation. ${ }^{20}$ In our study, the mean vault height was 524 microns, which showed a marginal reduction at the end of 12 months; however, it was safe enough to prevent cataract formation. In our study, none of the cases had any form of postoperative intraocular phakic IOL rotation, maintaining visual stability. Furthermore, preservation of endothelial cells is crucial and critical because it maintains corneal health throughout the life of a patient. ${ }^{21}$ Endothelial cell loss needs to be minimal by the judicious use of ophthalmic viscosurgical devices during lens implantation. Vasavada et al showed an $8.1 \%$ reduction in the endothelial cell count in the immediate postoperative period and showed only a $4 \%$ further reduction at the end of 3 years. ${ }^{19}$ The highest evidence of endothelial cell loss postphakic IOL implantation is from the multicentric US FDA trial (Visian implantable Collamer lens, STAAR Surgical, Nidau, Switzerland), which showed a reduction of $3.3 \pm$ $7.6 \%$ at 1 year (90\% confidence limits: $2.4 \%$ to $4.3 \%$ ) and $9.7 \pm 9.3 \%$ at 4 years. ${ }^{22}$ In our study, the endothelial cell loss was $5.1 \%, 5.8 \%$ and $7.3 \%$ at 1 month, 6 months and 12 months, respectively.

Cataract, glaucoma and infection are the three most important risks following phakic IOL implantation.

White to white (wtw) measurement is the most critical step in accurate phakic IOL calculation, improper measurement of the wtw diameter generates a faulty length of the phakic IOL, especially if the phakic IOL is smaller in length than the actual wtw diameter, it may lead to lower vault height and intraocular instability coaxing to cataract. ${ }^{23}$ In our study, none of the eyes had cataracts, we assume that the accurate calculation of the white-towhite diameter (wtw) maintained safe vault height and peripheral holes allowed a smooth flow of aqueous. However, long-term results are awaited.

Acute rise in intraocular pressure in the immediate post-op period is commonly attributed to nonpatent peripheral iridotomy. ${ }^{24}$ Hence, in our study, all patients were ensured of patent peripheral iris opening by performing retroilluminationtests with a visible red glow from peripheral opening in addition to pupillary glow prior to surgery.

Finally, post-operative intraocular infection is the most feared complication to any intraocular procedure, and prevention is the most crucial step in this regard. ${ }^{25-28}$ In our study, all patients were injected with preservative-free intracameral moxifloxacin to prevent any intraocular infection. ${ }^{28}$

The main limitations of the study are the short followup time, the small sample size and its retrospective nature. However, these preliminary results found that Refractive Intraocular Lens (Appasamy Associates Inc.) are safe and effective for treating cases of high myopia at short time follow-up (1 year), and similar to other posterior chamber 
phakic IOLs that have shown to be safe over much longer periods of time. Additional medium and long-term studies are warranted.

\section{Conclusion}

With the emerging trends in the field of refractive surgery, the phakic intraocular lens plays a significant role in spectacle-free vision. The short-term visual outcomes of RILs are promising despite the lower number of lenses implanted. However, RILs represent an important component of novel phakic lenses.

\section{Disclosure}

The authors report no conflicts of interest for this work.

\section{References}

1. Choi JH, Lim DH, Nam SW, Yang CM, Chung ES, Chung TY. Tenyear clinical outcomes after implantation of a posterior chamber phakic intraocular lens for myopia. $J$ Cataract Refract Surg. 2019;45(11):1555-1561. Epub 2019 Oct 3. PubMed PMID: 31587936. doi:10.1016/j.jcrs.2019.06.015

2. Martínez-Plaza E, López-Miguel A, Holgueras A, Barraquer RI, Alió JL, Maldonado MJ. Phakic intraocular lenses: recent advances and innovations. Lentes intraoculares fáquicas: recientes avances e innovaciones. Arch Soc Esp Oftalmol. 2020;95(4):178-187. doi:10.1016/j.oftal.2020.02.001

3. Pineda R, Chauhan T. Phakic Intraocular Lenses and their Special Indications. J Ophthalmic Vis Res. 2016;11(4):422-428. doi:10.4103/ 2008-322X.194140

4. Huang D, Schallhorn SC, Sugar A, et al. Phakic intraocular lens implantation for the correction of myopia: a report by the American Academy of Ophthalmology. Ophthalmology. 2009;116 (11):2244-2258. doi:10.1016/j.ophtha.2009.08.018

5. Santhiago MR, Giacomin NT, Smadja D, Bechara SJ. Ectasia risk factors in refractive surgery. Clin Ophthalmol. 2016;10:713-720. eCollection 2016. Review. PubMed PMID: 27143849; PubMed Central PMCID: PMC4844427. doi:10.2147/OPTH.S51313

6. Nakamura T, Isogai N, Kojima T, Yoshida Y, Sugiyama Y. Posterior Chamber Phakic Intraocular Lens Implantation for the Correction of Myopia and Myopic Astigmatism: a Retrospective 10-Year Follow-up Study. Am J Ophthalmol. 2019;206:1-10. Epub 2019 May 10. PubMed PMID: 31078536. doi:10.1016/j.ajo.20 19.04 .024

7. Galvis V, Villamil JF, Acuña MF, et al. Long-term endothelial cell loss with the iris-claw intraocular phakic lenses (Artisan ${ }^{\circledR}$ ). Graefes Arch Clin Exp Ophthalmol. 2019;257(12):2775-2787. doi:10.1007/ s00417-019-04506-9

8. Moya T, Javaloy J, Montés-Micó R, Beltrán J, Muñoz G, Montalbán R. Implantable collamer lens for myopia: assessment 12 years after implantation. J Refract Surg. 2015;31(8):548-556. doi:10.3928/1081597X-20150727-05

9. Jonker SMR, Berendschot TTJM, Ronden AE, Saelens IEY, Bauer NJC, Nuijts RMMA. Long-term endothelial cell loss in patients with artisan myopia and artisan toric phakic intraocular lenses: 5- and 10-year results. Ophthalmology. 2018;125 (4):486-494. doi:10.1016/j.ophtha.2017.08.011

10. MacRae S, Holladay JT, Hilmantel G, et al. Special report: american academy of ophthalmology task force recommendations for specular microscopy for phakic intraocular lenses. Ophthalmology. 2017;124 (1):141-142. doi:10.1016/j.ophtha.2016.09.034
11. Alfonso JF, Fernández-Vega-Cueto L, Alfonso-Bartolozzi B, Montés-Micó R, Fernández-Vega L. Five-year follow-up of correction of myopia: posterior chamber phakic intraocular lens with a central port design. $J$ Refract Surg. 2019;35(3):169-176. doi:10.3928/1081597X-20190118-01

12. Galvis V, Carreño NI, Tello A, Laiton AN. Severe pigment dispersion after iris-claw phakic intraocular lens implantation. Indian J Ophthalmol. 2017;65(12):1492-1494. doi:10.4103/ijo.IJO_743_17

13. Balparda K, Vanegas-Ramírez CM, Segura-Muñoz L, GómezLondoño M. Contralateral posterior chamber phakic intraocular lens implantation as rehabilitation of refractive lens exchange with a monofocal intraocular lens in a young, nonpresbyopic, bilateral highly-myopic patient. Case Rep Ophthalmol Med. 2019; 2019:8791071. doi:10.1155/2019/8791071

14. Subudhi P, Patro S, Khan Z, Subudhi BNR, Sitaram S. Refractive outcomes of implantation of an implantable phakic copolymer lens with peripheral holes in the intraocular posterior chamber in moderate to high myopia patients: a single- surgeon series. Clin Ophthalmol. 2019;23(13):1887-1894. doi:10.2147/OPTH. S215821

15. Bianchi GR. Initial results from a new model of posterior chamber implantable phakic contact lens: IPCL V2.0. Med Hypothesis Discov Innov Ophthalmol. 2019;8(2):57-63.

16. Sachdev G, Ramamurthy D. Long-term safety of posterior chamber implantable phakic contact lens for the correction of myopia. Clin Ophthalmol. 2019;13:137-142. doi:10.2147/OPTH.S185304

17. Stodulka P, Slovak M, Sramka M, Polisensky J, Liska K. Posterior chamber phakic intraocular lens for the correction of presbyopia in highly myopic patients. $J$ Cataract Refract Surg. 2020;46(1):40-44. PubMed PMID: 32050231. doi:10.1097/j.jcrs.0000000000000033

18. Tang Y, Ye J. Phakic posterior chamber intraocular lens with a central hole in treating patients with moderate to high myopia: a meta-analysis. J Ophthalmol. 2019;2019:9496326. eCollection 2019. PubMed PMID: 31781381; PubMed Central PMCID: PMC6875278. doi:10.1155/2019/9496326

19. Vasavada V, Srivastava S, Vasavada SA, Sudhalkar A, Vasavada AR, Vasavada VA. Safety and efficacy of a new phakic posterior chamber IOL for correction of myopia: 3 years of follow-up. J Refract Surg. 2018;34(12):817-823. PubMed PMID: 30540364. doi:10.3928/ 1081597X-20181105-01

20. Sánchez-González JM, Alonso-Aliste F, Perea-Peña G, RachwaniAnil R, Márquez-de-Aracena-Del-Cid R, Rocha-de-Lossada C. Anterior chamber angle width, central vault and intraocular pressure changes after 12 months of Visian collamer lens implantation. Int Ophthalmol. 2020;40(8):2047-2053. PubMed PMID: 32314324. doi:10.1007/s10792-020-01381-w

21. Feizi S. Corneal endothelial cell dysfunction: etiologies and management. Ther Adv Ophthalmol. 2018;10:2515841418815802. doi:10.1177/2515841418815802

22. Sanders DR, Doney K, Poco M; ICL in Treatment of Myopia Study Group. United States Food and Drug Administration clinical trial of the implantable collamer lens (ICL) for moderate to high myopia: three-year follow-up. Ophthalmology. 2004;111(9):1683-1692. PubMed PMID: 15350323.

23. Tan TE, Liu YC, Jayasinghe LS, Mehta JS. Intraoperative optical coherence tomography vault measurement in posterior chamber phakic intraocular lens implantation. J Refract Surg. 2017;33 (4):274-277. PubMed PMID: 28407168. doi:10.3928/1081597X20170111-05

24. Zaldivar R, Davidorf JM, Oscherow S. Posterior chamber phakic intraocular lens for myopia of -8 to -19 diopters. J Refract Surg. 1998;14:294-305.

25. Haripriya A, Chang DF. Intracameral antibiotics during cataract surgery: evidence and barriers. Curr Opin Ophthalmol. 2018;29 (1):33-39. Review. PubMed PMID: 29095716. doi:10.1097/ ICU.0000000000000445 
26. Galvis V, Tello A, Sánchez MA, Camacho PA. Cohort study of intracameral moxifloxacin in postoperative endophthalmitis prophylaxis. Ophthalmol Eye Dis. 2014;6:1-4. doi:10.4137/OED.S13102

27. Bowen RC, Zhou AX, Bondalapati S, et al. Comparative analysis of the safety and efficacy of intracameral cefuroxime, moxifloxacin and vancomycin at the end of cataract surgery: a meta-analysis. $\mathrm{Br}$ $J$ Ophthalmol. 2018;102(9):1268-1276. doi:10.1136/bjophthalmol2017-311051
28. Galvis V, Tello A, Camacho PA, Rey JJ. Comment on: antibiotic prophylaxis in cataract surgery - an evidence-based approach. Indian J Ophthalmol. 2018;66(4):603. doi:10.4103/ijo.IJO_1309_17

\section{Publish your work in this journal}

Clinical Ophthalmology is an international, peer-reviewed journal covering all subspecialties within ophthalmology. Key topics include: Optometry; Visual science; Pharmacology and drug therapy in eye diseases; Basic Sciences; Primary and Secondary eye care; Patient Safety and Quality of Care Improvements. This journal is indexed on PubMed

Submit your manuscript here: https://www.dovepress.com/clinical-ophthalmology-journal
Central and CAS, and is the official journal of The Society of Clinical Ophthalmology (SCO). The manuscript management system is completely online and includes a very quick and fair peer-review system, which is all easy to use. Visit http://www.dovepress.com/ testimonials.php to read real quotes from published authors. 